\title{
Más allá del par forma-contenido. Una lectura de las fuentes biológicas de la estética deleuzeana
}

\section{Beyond form and content: Reading the biological sources of Deleuze's aesthetics}

\author{
GUADALUPE LUCERO \\ Universidad de Buenos Aires
}

Recibido: $27 / 10 / 14$

Aceptado: 07/05/15

\section{RESUMEN:}

La originalidad que define la lectura deleuzeana de las artes es su crítica implícita a toda antropología o psicología del artista y del espectador, y a todo abordaje de la obra dependiente de la tradición hermenéutica, de las teorías del lenguaje y de la semiología estructuralista. El problema de la animalidad y de la vida en general en relación con el arte parece responder, de un modo inédito, al desdibujamiento de las esferas que la estética clásica distinguía como categorías escindidas para el análisis de la obra de arte; el autor, la obra, el espectador. En este artículo proponemos un recorrido por algunos aspectos de las teorías de la individuación y lo viviente en Simondon, Bergson y von Uexküll para comprender su uso y función en la estética deleuzena.

\section{PALABRAS CLAVE:}

DELEUZE, ESTÉTICA, SIMONDON, BERGSON, VON UEXKÜLL

\section{ABSTRACT:}

The originality of Deleuze aesthetics is its implicit refuse of any anthropology o psychology of the artist or the spectator, and also a refusal of hermeneutics, language theories and structuralist semiology towards an analysis of the work of art. The problem of animality and life in general in relation to art seems to respond, in an unprecedented way, to the fading of those which classical aesthetics regarded as split topics for the analysis of the work of art, i.e., author, 
work of art, spectator. This paper points out some relevant aspects of individuation and life theories in Simondon, Bergson and von Uexküll, so as to understand their use and function in Deleuze aesthetics.

KEY WORDS:

DELEUZE, AESTHETICS, SIMONDON, BERGSON, VON UEXKÜLL

LA ORIGINALIDAD DE LA ESTÉTICA DELEUZEANA se asienta en al menos dos pilares: la crítica implícita a toda antropología o psicología del artista y del espectador; y el rechazo de todo abordaje de la obra dependiente de la tradición hermenéutica, de las teorías del lenguaje y de la semiología estructuralista. Como ha señalado Anne Sauvagnargues en Deleuze. Del animal al arte, quizás la particularidad de la reflexión sobre el problema de las artes radique en su paralelo con una reflexión específica por el modo de ser del animal y de la vida en general. Esta reflexión, como intentaremos mostrar aquí, implica ante todo una redefinición del privilegio del concepto de individuo, y con ella una crítica de la relación entre forma y contenido. Pero muy lejos del espíritu deleuzeano están las aseveraciones en torno al fin del arte o el fin de la estética. La crítica es efecto de la construcción conceptual que Deleuze erige para abordar el problema del arte, y que tiene en el concepto de ritornelo, quizás, su momento más acabado. Frente a la estética moderna que tenía como eje fundamental un sujeto productor y un sujeto de experiencia, el advenimiento del problema de la animalidad en relación con el arte parece responder, de un modo inédito, al desdibujamiento de las esferas que la estética clásica distinguía como categorías escindidas para el análisis de la obra de arte; el autor, la obra, el espectador. A través de una comprensión de lo viviente que rechaza el privilegio antropológico no sólo se modifica la distinción clara entre artista y espectador, sino especialmente el sentido de la obra. Así veremos que gracias a Simondon, resultará inviable una lectura de la obra de arte en términos de forma y contenido; que a través de Bergson y de la oposición virtual-actual el carácter simbólico de la obra de arte se encuentra transvalorado; que la noción de afecto tal como es pensada en Spinoza pero especialmente hibridada con von Uexküll abre una nueva concepción de la expresión artística y de su vínculo con lo sensorial.

\section{LA MODULACIÓN}

El abandono de la articulación entre forma y contenido en la interpretación deleuzeana de la obra de arte se tramita a través de un doble alejamiento. Por un lado, el rechazo del arte figurativo, entendido como ilustración o narración, ya que el arte no tiene «ni modelo que representar, ni historia que contar». ${ }^{1}$ Por otro, el alejamiento de la lógica formalista del arte, que estabiliza el material

1 G. Deleuze, Francis Bacon. Lógica de la sensación, tr.I. Herrera. Madrid: Arena, 2002, p. 14 
sensible a través de un código. El material pasaría aquí a través de una criba binaria que fija y reorganiza el desanclaje resultante del abandono de la ilustración. Frente a estos extremos, que en última instancia no son sino aquellos del contenido y de la forma, Deleuze propondrá una concepción de la obra de arte como expresión afectiva que implica siempre un devenir, un entre-dos, y que encuentra en la noción de modulación el modo más adecuado para nombrar el particular movimiento que aquella opera sobre determinado material.

Para comprender la importancia y alcance de la noción de modulación, es necesario remitirnos a su uso en el contexto simondoniano. En la introducción a La individuación a la luz de las nociones de forma y de información, Simondon presta especial atención al rol que cumple el esquema hilemórfico en la comprensión del fenómeno de la individuación. El prejuicio fundamental que subyace en ella y que es necesario desandar es que existiría «un principio de individuación anterior a la individuación misma, susceptible de explicarla, de producirla, de conducirla». ${ }^{2}$ Es decir, la historia de la filosofía ha planteado el problema de la individuación a partir de la concesión de un «privilegio ontológico al individuo constituido», ${ }^{3}$ dejando sin explicar, por lo tanto, la ontogénesis misma. Bergson realiza una crítica semejante respecto de la explicación lógica y su coerción sobre la vida:

En vano intentamos encajar al ser vivo en tal o cual marco nuestro. Todos lo marcos se rompen y se resquebrajan. Son demasiado estrechos y sobre todo demasiado rígidos para lo que quisiéramos meter en ellos. Nuestro razonamiento, tan seguro de sí mismo cuando se mueve entre cosas inertes, se siente a disgusto en este nuevo terreno. ${ }^{4}$

La inteligencia no es la facultad suprema de conocimiento porque su modo de operar -analítico y mecánico-descompone en partes lo que es fluido. Si el razonamiento es adecuado, quizás el corset conceptual de la inteligencia sirva para abordar los objetos inertes pero no el fluir vital. La distinción neta entre lo orgánico y lo inorgánico es una consecuencia de las operaciones de la inteligencia y la percepción humana, «el seccionamiento de la materia en cuerpos orgánicos e inorgánicos es relativo a nuestros sentidos y a nuestra inteligencia», pero no resulta adecuado si consideramos la materia «como un todo indiviso... un fluir más que una cosa». ${ }^{5} \mathrm{El}$ estado fluido de la materia es

2 G. Simondon, La individuación a la luz de las nociones de forma y de información, tr. P. Ires, Buenos Aires: Cactus-La Cebra, 2009, p. 23.

3 Ibid., p. 24.

4 H. Bergson, La evolución creadora, tr. M. L. Pérez Torres, Barcelona: Planeta-De Agostini, 1994, p. 10

5 Ibid. p. 170 
el que encontramos en la maravillosa descripción del mundo de imágenes del primer capítulo de Materia y memoria ${ }^{6}$ Esta materia deviniente es quizás el punto común que permite hibridar las teorías de Simondon y Bergson, operación que produce la particular lectura deleuzeana.

En el texto referido, Simondon analiza en primer lugar la individuación física, es decir, la individuación de los objetos y los seres no vivos porque es allí donde primariamente opera la lógica hilemórfica. Como señalaba Heidegger en "El origen de la obra de arte", la cosa preconcebida como materia informada es la que corresponde esencialmente a los útiles, a los objetos fabricados por el hombre. ${ }^{7}$ Se trata también de la observación bergsoniana a propósito de que los entes del mundo son para la inteligencia herramientas, útiles. Y Simondon toma un ejemplo técnico -la fabricación de un ladrillo-para explicar en qué consiste el carácter de prejuicio de este preconcepto. La fabricación del ladrillo no se explica indicando que a la arcilla, materia amorfa, se le imprime la forma abstracta del ortoedro. Es necesario construir un molde que limite la materia, fabricarlo con los elementos necesarios para ejercer y soportar una presión específica. Por otro lado, la materia -la arcilla - debe estar tratada a fin de conseguir una masa con propiedades homogéneas, que permita su total acoplamiento con el molde. El molde no imprime una forma abstracta a una materia también abstracta, sino que modula las propiedades de una materia a la que se le han determinado ya las características necesarias para semejante modulación. La materia tiene entonces «la propiedad positiva que le permite ser moldeada. [...] La forma pura ya contiene gestos, y la materia primera es capacidad de devenir; los gestos contenidos en la forma encuentran el devenir de la materia y lo modulan». ${ }^{8} \mathrm{El}$ molde es en realidad una materia que ejerce presión, que detiene el movimiento de otra materia, y que no funciona en tanto que forma, sino en tanto que límite en cada punto. La materia no es forma en potencia, sino que la energía potencial de la materia, contenida en sus propiedades, es la que determina las fuerzas que operarán sobre el molde. Vemos que se modifica aquí un punto central: no es la forma la que es actualizante, la que opera, y por lo tanto, el agente que produce un objeto dado:

La relación entre materia y forma no se lleva a cabo entonces entre materia inerte y forma que viene de afuera; entre materia y forma existe una operación común y a un mismo nivel de existencia; este nivel común de existencia es el de la fuerza, que proviene de una energía momentáneamente vehiculizada por la materia, pero

6 Cfr. H. Bergson, Materia y memoria. Ensayo sobre la relación del cuerpo con el espiritu, tr. P. Ires, Buenos Aires: Cactus, 2006.

7 Cfr. M. Heidegger, "El origen de la obra de arte" en Caminos de bosque, tr. H. Cortés y A: Leyte, Madrid: Alianza, 1995.

8 G. Simondon, op. cit., p. 52. 
extraída de un estado del sistema interelemental total de dimensión superior y que expresa las limitaciones individuantes. ${ }^{9}$

En esta operación común es la materia la que porta la mayor energía, la mayor fuerza plástica, mientras que la forma es más bien fuerza limitante. En este sentido, la materia deviene, mientras que la forma no. Simondon detecta con cierta ironía el punto de vista desde el que se sostiene el esquema hilemórfico: aquel del hombre teórico, que sabe qué es lo que entra -en el taller del artesano o del artista, en la fábrica, en las instituciones sociales- y qué es lo que sale, pero desconoce totalmente el proceso real. Es la figura del hombre libre frente al esclavo, como lúcidamente señala Simondon. Y aquí nuevamente reencontramos el hilo bergsoniano: se trata de un modo de comprender el mundo de acuerdo con el uso que le damos y en este sentido, como ya indicaba Platón en el libro X de República, es el que usa, no el que fabrica efectivamente, quien deberá definir la forma de los objetos. Es que en la preeminencia del esquema hilemórfico, es decir de un esquema que parece ser técnico, como se desprende también del texto de Heidegger, para pensar lo individuado en general -también la individuación biológica-se requiere de una particular concepción del mundo mediada por la lógica social del trabajo:

En el origen del esquema hilemórfico, el término medio entre el dominio viviente y el dominio técnico parece haber sido la vida social. Lo que el esquema hilemórfico refleja en primer lugar es una representación socializada del trabajo y una representación igualmente socializada del ser viviente individual. [...] La operación técnica que impone una forma a una materia pasiva e indeterminada no sólo la operación abstracta considerada por el espectador que ve lo que entra al taller y lo que sale de allí sin conocer la elaboración propiamente dicha. Es esencialmente la operación dirigida por el hombre libre y ejecutada por el esclavo [...] la verdadera pasividad de la materia es su disponibilidad abstracta tras la orden dada que otros ejecutarán. [...] El carácter activo de la forma, el carácter pasivo de la materia, responden a las condiciones de la transmisión de la orden, la cual siempre supone jerarquía social: es en el contenido de la orden que el índice de la materia es un indeterminado, mientras que la forma es determinación, expresable y lógica. ${ }^{10}$

Este fragmento condensa la potencia de la teoría simondoniana en vistas a lo que nos ocupa. La individuación bajo la lógica del par forma-materia es ideológica, y supone por un lado la presunción de la jerarquía social en el trabajo y la sobrevaloración de la orden es decir, del lenguaje en tanto que

9 Ibid., p. 53.

10 Ibíd., pp. 65-66. 
dispositivo de enunciación, frente al trabajo propiamente dicho, es decir, el moldeado de la materia. Por otro, supone la homologación entre esta estructura correspondiente al dominio social y la individuación física y biológica en general. Una antropologización de los procesos de individuación. Se anula el carácter activo, deviniente, energético, plástico de la materia al determinarla como mera pasividad a favor de una actividad formal que sería análoga a la potencia informante de la orden.

Para comprender el proceso individuante es necesario trabajar a otra escala y analizar el molde mismo. Debemos distinguir el molde, que limita la materia en un tiempo determinado -como en el caso del ladrillo-, del modulador, que funciona como un molde temporal continuo, es decir, como un molde que no busca llevar a la materia a un nuevo estado de equilibro durable sino que la materia mantiene allí siempre cierto estado de variabilidad en función de la energía que porta. Esta distinción permite matizar la relación de molde, distinguiendo al menos tres posibilidades en el moldeado, la modulación (los casos extremos) y el modelado. Si retomamos desde aquí la cuestión de la individuación observamos que la objeción de Simondon se dirige fundamentalmente a la atención puesta en el punto de partida y el punto de llegada, olvidando el devenir, lo que sucede en medio. Vemos la cercanía entre este acento y la crítica bergsoniana a propósito de la comprensión del movimiento. La ilusión antigua y también la moderna yerran su objetivo al buscar en los momentos detenidos, en los puntos fijos, la esencia de lo móvil. La comprensión del vínculo entre forma y materia en términos de modulación, donde la materia implica ya una determinada elaboración y donde a la vez la forma es más bien la impresión de ciertos gestos, de ciertos límites, también determinados por cierta elaboración, resuena evidentemente en la problematización de la obra de arte. ${ }^{11}$

Es en Francis Bacon. Lógica de la sensación donde Deleuze explicita el vínculo entre el concepto de modulación simondoniana y su propio concepto estético de diagrama. El diagrama «actúa como un modulador» ${ }^{12}$ y evita los

11 La Teoría estética de Adorno dedica un apartado fundamental al vínculo entre forma y contenido, en términos por momentos convergentes a la crítica simondoniana del esquema hilemórfico. Allí Adorno indica que la limitación del concepto de forma radica en un uso que olvida el carácter creativo de las dimensiones que informa. Por ejemplo, el olvido del rol formante de los colores en pintura o de las alturas en la música. Sin embargo, la forma converge con la crítica cuando se la considera como «todo aquello en lo que la mano dejó sus huellas al pasar»y «su papel es poner límites a lo formado», es decir, al material que llega históricamente conformado. La forma es así «contenido sedimentado». Esta lectura resulta aún más potente al denegar la noción de «contenido» a favor de una idea de «material» que es «plenamente histórico». Cfr. T. Adorno, Teoría estética, tr. J. Navarro Pérez, Madrid: Akal, 2004. Esp. «Forma y contenido» y «El concepto de material».

12 G. Deleuze, Francis Bacon. Lógica de la sensación, op. cit. p. 122. 
caminos en los que el arte posmimético no terminaría de conjurar las viejas categorías de la forma y el contenido. El abandono de la figuración implica la necesidad de tramitar el caos que habita el fondo de los clichés miméticos. Deleuze identifica dos caminos que, respecto de la relación con el caos asediante, el diagrama permite sortear: la vía abstracta-codificada y la vía informal-caótica. En el primer caso se trata de la elaboración de un «código simbólico ${ }^{13}$ que haría pasar el material sensible (pictórico, musical, gestual) por una criba binaria que lo estabilizaría, criba trascendente que abre un sensible espiritual pero que parece deshacerse de un solo golpe de la densidad motívica del material. El caos se conjura por indiferencia: nada monstruoso, nada incomprensible, basta analizar la pureza de las formas y los elementos. Los ejemplos deleuzeanos señalan aquí a Mondrian y Kandinsky, podríamos agregar el serialismo integral como deriva propiamente musical, donde el efecto sonoro depende del control paramétrico total. Se trata de un formalismo que invierte a la vez que renaturaliza el comercio entre la forma y el contenido: la forma no agrupa ya lo diverso en la unidad sino que el artificio compositivo se presenta a sí mismo como contenido último. El gesto contrario es aquel en el que el material invade el plano compositivo como singular particularísimo que obstruye toda tendencia unitaria en la forma. Es el caso del expresionismo abstracto en el que

El trazo-línea y la mancha-color van justo hasta el extremo de su función: no ya transformación de la forma sino una descomposición de la materia que nos entrega sus lineamientos y sus granulaciones. ${ }^{14}$

Pero el problema que el arte informal presenta es que el ascenso del caos amenaza con llevarse consigo la obra. ${ }^{15}$ Por ello Bacon presenta una tercera

\section{Ibid. p. 105.}

14 Ibid. P. 107.

15 ¿Debemos entender este ascenso del caos pictórico en el arte informal a partir de aquello que Adorno llamó música informal? En "Vers une musique informelle", Adorno abordaba lo que consideraba un escollo en la música de posguerra; tanto la absolutización del sonido hasta tornarlo un hecho puramente físico, como, por el contrario, la absolutización de la relación y la forma, que tomaba la lógica de lo mecánico contra la tendencia orgánica y deviniente de la obra. La informalidad adorniana no es aquí equivalente al caos del expresionismo abstracto, sino más bien el intento de abordar el problema del caos sin conjurarlo: «la música informal sería una música que pierde el miedo porque lo refleja e irradia; no se deja tutelar por él. Ella sabría distinguir entre lo caótico, de lo cual nunca se estuvo tan lejos, y la mala conciencia de la libertad en la que la no-libertad pervive». T. W. Adorno, « Vers une musique informelle » en Quasi una fantasia. Escritos musicales I-III, tr. A. Brotons Muñoz y A. Gómez Schneekloth, Madrid : Akal, p.523. Esa suerte de camino del medio de la música informal, que la acerca a la opción diagramática deleuzeana, implica un paso previo por la organización absoluta, 
vía diagramática, que construye, contra los lenguajes digitales de la abstracción, lenguajes analógicos que actúan por modulación. Del mismo modo que reconocemos la diferencia entre un sintentizador analógico y un sintetizador digital por el tipo de vínculo que establecen entre los elementos que deben reunir - de un lado conexión de heterogéneos, del otro, traducción en función de un código-, el diagrama opera, en el caso de Bacon, un movimiento de modulación del color como elemento pictórico.

\section{De Simondon a Bergson}

Como indica Sauvagnargues, ${ }^{16}$ Deleuze parte de Simondon para arribar a consecuencias bergsonianas, ya que la lectura de la individuación en términos de movimiento de actualización permite modular la teoría simondoniana hacia la conceptualización bergsoniana. Para actualizarse lo virtual debe «crear sus propias líneas de actualización $»^{17} \mathrm{y}$ en este sentido lo virtual en Bergson viene a criticar el par posible/real. Lo posible es siempre deficiente respecto de lo real, mientras que lo virtual, como es el caso del medio energético, no implica ninguna deficiencia respecto de lo real-es totalmente real-, sino que se opone a sus actualizaciones. Simondon y Bergson dan a Deleuze el marco necesario para su teoría de lo virtual porque permiten pensar el devenir como lo esencial, denunciando la estaticidad o el reposo como ilusorios. Es así que lo virtual nada tiene que ver con lo meramente indeterminado. Como veíamos a propósito de la materia amorfa simondoniana, no se trata de carencia de propiedades, más bien al contrario. Las singularidades que pueblan la materia se movilizan de un particular modo en el encuentro con el germen estructurante. Pero el individuo concreto que resulta, que se genera como resto del acto de individuación, es absolutamente acontecimental y se explica en función de la singularidad de su génesis. Esto quiere decir que el individuo no porta sustancialmente sus propiedades, sino que éstas surgen de la particular relación que desencadenó su génesis. Así el resto individuado es como una solución que resolvió un estado virtual, pero ese estado virtual mantiene su carácter problemático, es decir, su potencia diferencial. La obra de arte es aquí un ejemplo privilegiado:

Cuando la obra de arte invoca una virtualidad en la que se sumerge, no invoca ninguna determinación confusa, sino la estructura completamente determinada

de la que luego será necesario recuperar el elemento subjetivo. La tercera vía deleuzeana, por su parte, toma el camino contrario, es necesario en primer lugar pasar por el caos, para extraer de allí los nuevos elementos motívicos.

16 Cfr. A. Sauvagnargues, Deleuze. Del animal al arte, tr. I. Agoff, Buenos Aires: Amorrortu, 2006, p. 34

17 G. Deleuze, El Bergsonismo, tr. L. Ferrero Carracedo, Madrid: Cátedra, 1987, p. 102. 
que forman sus elementos diferenciales genéticos, elementos «virtualizados», «embrionizados». Los elementos, las variedades de relaciones, los puntos singulares, coexisten en la obra o en el objeto, en la parte virtual de la obra o del objeto, sin que pueda asignar un punto de vista privilegiado sobre los otros, un centro que sería unificador de otros centros. ${ }^{18}$

El problema que la obra actualiza no se resuelve en la solución, sino que las condiciones de lo problemático se mantienen frente a las actualizaciones que nunca proceden por semejanza, no son copias degradadas del problema, sino que proceden por diferenciación o disparidad. En este sentido lo virtual es ante todo -así como la materia con un potencial de desequilibrio energético en Simondon- problemático:

Siempre reencontramos leyes comunes a estas líneas de actualización o de diferenciación. Entre la vida y la materia, entre la distensión y la contracción, existe una correlación que da cuenta de la coexistencia de sus grados respectivos en el Todo virtual, y de su relatividad esencial en el proceso de actualización. Cada línea de la vida se vincula con un tipo de materia, que no es solo un medio exterior, sino uno en función del cual el viviente, respecto de la materia, aparece ante todo como postulación de problema, y capacidad de resolver problemas. ${ }^{19}$

Es en este sentido que Deleuze puede afirmar en Diferencia y repetición que la realidad de lo virtual es la de una tarea por cumplir, ${ }^{20}$ es decir la realidad de un problema que brinda el horizonte para las soluciones que no agotan su carácter problemático. Simondon y Bergson funcionan en el sistema deleuzeano como una doble máquina conceptual orientada a deshacer la estructura del sujeto como sustancia. El sujeto es para Deleuze un concepto que tuvo dos funciones: por un lado de universalización en un contexto donde las viejas esencias son reemplazadas por los actos de consciencia, por otro de individuación, donde la persona ${ }^{21}$ viene a relevar la noción de individuo como cuerpo y/o alma; ${ }^{22}$ la crítica deleuzeana tiene como objetivo de mínima el desandamiaje

18 G. Deleuze, Diferencia y repetición, tr. S. Delpy y H. Beccacece, Buenos Aires: Amorrortu, 2002, p. Différence et répétition. París: PUF, 1993, p. 315.

19 G. Deleuze, El bergsonismo, ed. cit., p. 107.

20 G. Deleuze, Diferencia y repetición, ed. cit., p. 319.

21 Sobre la persistencia de la operación moderna en torno al concepto de persona véase R. Esposito, Tercera Persona. Política de la vida y filosofia de lo impersonal, tr. C. R. Molinari Marotto, Buenos Aires: Amorrortu, 2009.

22 Cfr. G. Deleuze, « Réponse à une question sur le sujet » en Deux régimes de fous et autres textes (1975-1995) Édition préparée par David Lapoujade, París : Minuit, 2003, p. 326. [Hay traducción castellana: Dos regímenes de locos. Textos y entrevistas (1975-1995), tr. J. L. Pardo. Valencia: Pre-textos, 2008] 
de estas dos funciones. Pero esta operación tiene una peculiaridad que quizás distingue a Deleuze entre sus contemporáneos. Se trata menos de destruir la función sujeto que de extenderla excesivamente, hasta que pierde su eficacia trascendente. ${ }^{23}$ Para evaluar la potencia de un concepto de la tradición, en este caso el de sujeto, es necesario preguntarse si puede tomar nuevas funciones que modifiquen su efectividad. ${ }^{24}$ Un movimiento característico de la operación deleuzeana será mostrar cómo estos conceptos que implican un problema particular son efectos de un campo cuyas variables podrían arrojar una solución distinta. En este sentido, cuando en Diferencia y repetición Deleuze analiza las síntesis temporales que en última instancia producen al sujeto como resto, analiza específicamente la primera que es el hábito y que se comprende pasivamente. No es actuando que adquirimos un hábito sino contemplando. Se trata más precisamente de una contracción, no un acto consciente. La expresión contraer un hábito ilustra en este sentido su carácter pasivo. Podríamos pensar que se trata de las síntesis perceptivas, de la respuesta con la cual los órganos sensoriales responden a un medio y envuelven en el límite de la relación entre recepción y reacción esa contracción que para Deleuze es también un signo. Sin embargo, ya los órganos son efectos de otras síntesis:

En el orden de la pasividad constituyente, las síntesis perceptivas remiten a síntesis orgánicas, así como la sensibilidad de los sentidos, a una sensibilidad primaria que somos. Somos agua, tierra, luz y aire contraídos, no sólo antes de reconocerlos o de representarlos, sino antes de sentirlos. Todo organismo es, en sus elementos receptivos y perceptivos, pero también en sus vísceras, una suma de contracciones, de retenciones y de esperas. ${ }^{25}$

Vemos que las síntesis pasivas en tanto que fundamento de algo así como una protosubjetividad se encuentran en todos los niveles, luz, aire, órganos, etc. En el cuarto capítulo de La imagen-movimiento. Estudios sobre cine 1 Deleuze realiza un extenso comentario al primer capítulo de Materia y memoria para mostrar cómo el universo de las imágenes, incluidas las imágenes cinematográficas, posee una ontología propia, indiferente del problema del sujeto, donde éste es más bien producto de una de las posibles relaciones que el universo

23 No es el único caso en el que Deleuze rechaza toda lógica de la muerte de o del fin de. Lo mismo sucede con la filosofía y con el arte. Pero este rechazo no debe comprenderse como un mero retorno a. Se trata más bien de la reapropiación de los conceptos y de los sistemas filosóficos de la tradición para extender los problemas que implican a otros campos dando, como sucede con el caso del concepto de sujeto, un uso «ilegítimo» que termina desarticulando los efectos que lo determinaban.

24 Cfr. Ibid., p. 327.

25 G. Deleuze, Diferencia y repetición, ed. cit., p. 123. 
de imágenes puede presentar. El sujeto, antes que una lámpara que ilumina el mundo -foco de espontaneidad y acción-, es una caja negra que detiene el movimiento, lo desacelera para devolverlo al universo de imágenes levemente desviado. El acento en la pasividad del hábito busca por un lado denegar el carácter activo de la subjetividad como determinante, y a la vez extiende el domino de lo subjetivo al extremo de borrar sus potencias jerarquizantes, multiplicando microsujetos y protosujetos, ojos y placas sensibles. En La imagen-movimiento solo al final se alcanza la forma de la imagen-acción -aquella que caracteriza el modo de hacer del sujeto como quien responde a un medio-porque antes $\mathrm{y}$ en su fundamento insisten otras formas que la preceden y la condicionan.

La preeminencia de la imagen en el análisis precedente sugiere una salida por la tangente al escollo que la estética derivada de Heidegger y Hegel nos conduce; a saber, su dependencia de la palabra. ¿Podemos aventurar que la trampa antropológica ${ }^{26}$ es burlada por medio de un giro imaginario que desactiva todo giro lingüístico? Este parece ser el camino que abre la particular hibridación entre Simondon y Bergson: una lógica de la individuación indiferente a toda forma trascendente, un mundo imaginario indiferente a toda percepción... Quizás los alcances de este giro encuentren su formulación más precisa en las críticas a los postulados de la lingüística en Mil Mesetas. Solo desarmando la máquina lingüística se podrá acceder a una máquina literaria afectiva que revele toda su potencia política.

\section{PoBREZA DE MUNDO}

J. von Uexküll constituye una referencia ineludible para considerar tanto la concepción deleuzeana de la vida y del animal, como la semiótica que estará a la base de la mencionada desactivación lingüística. El biólogo estonio-alemán se opuso a la comprensión mecanicista y también evolucionista de la naturaleza, y abrió la clave de lectura ineludible para comprender los debates en torno de lo humano y lo animal en parte importante de la filosofía europea del siglo XX. De acuerdo con Agamben las investigaciones de von Uexküll

Expresan el abandono sin reservas de toda perspectiva antropocéntrica en las ciencias de la vida y la radical deshumanización de la imagen de la naturaleza (no tiene que sorprender, por lo tanto, que ejercieran una fuerte influencia tanto sobre Heidegger -el filósofo del siglo XX que más se esforzó por separar al hombre del viviente- como sobre aquel otro, Gilles Deleuze, que trató de pensar el animal de modo absolutamente no antropomórfico). ${ }^{27}$

26 Pensamos aquí en el concepto agambeniano de «máquina antropológica» tal como se aventura en Lo abierto.

27 G. Agamben, Lo abierto, tr. F. Costa y E. Castro, Buenos Aires: Adriana Hidalgo, 
Agamben acierta al señalar estos polos opuestos de la recepción, ya que la tensión entre Heidegger y Deleuze, aunque no expresamente abordada por el filósofo francés, recorre la interpretación deleuzeana de von Uexküll, derivando de su etología consecuencias por momentos opuestas palmo a palmo a las heideggerianas. Es por ello que revisitaremos brevemente algunas de las tesis fundamentales que Heidegger ha inscripto en la estela de von Uexküll para luego abordar la interpretación deleuzeana.

Pero antes daremos un pequeño rodeo por el ejemplo favorito y recurrente para explicar la noción central de la concepción uexkülleana de la naturaleza, la Umwelt. Se trata, claro, del caso de la garrapata. Von Uexküll nos explica que el mundo circundante [Umwelt] de la garrapata se compone de tres caracteres afectivos. En Spinoza. Filosofía práctica Deleuze lo describe del siguiente modo:

El primero, luminoso (trepar a lo alto de una rama); el segundo, olfativo (dejarse caer sobre el mamífero que pasa bajo la rama); el tercero, calorífico (buscar la zona pelada y más cálida). Tan sólo un mundo de tres afectos, rodeado por todos los acontecimientos del bosque inmenso. ${ }^{28}$

El mundo circundante [Umwelt] se distingue del entorno o del espacio objetivo [Umgebung] en el que a menudo el hombre sitúa al animal. La garrapata no vive en el campo, así como el pez no vive en el agua, si por estos sintagmas entendemos un entorno abstracto dentro del cual podríamos incluir al animal en cuestión junto con todo aquello que el hombre podría observar en él. La garrapata no ve ni oye, no siente de ese entorno más que las señales que puede percibir y que desencadenan a su vez una acción específica. Pero ese mundo debe ser comprendido a partir de esos caracteres afectivos, y no en relación con los caracteres faltantes, carentes, posibles, ausentes. Agamben es muy certero cuando nos recuerda que la teoría de von Uexküll es contemporánea de las primeras vanguardias. Hay algo en común entre la caracterización de los mundos animales, y el intento analítico de construir una obra a partir de uno o dos elementos, de practicar un ascetismo de los medios, pero para explotar y llevar hasta sus propios límites las potencias de los mismos. Este será un punto central para comprender la concepción deleuzeana de von Uexküll.

Esta pobreza afectiva lleva a Heidegger a tomar como punto de partida el ejemplo de von Uexküll para deducir la condición del animal como pobre de mundo. El propio von Uexküll parece abrir esta lectura cuando indica que «la riqueza del mundo que rodea la garrapata desaparece y se reduce a una

2006, pp.79-80.

28 G. Deleuze, Spinoza. Filosofía práctica, tr. A. Escohotado. Barcelona: Tusquets, 1984, p. 152. 
forma pobre que consiste esencialmente en tres caracteres perceptivos y tres caracteres activos -su medio». ${ }^{29}$ Esta pobreza, explica Heidegger, no debe entenderse como un mero «menos» del animal que, frente al hombre configurador de mundo, lo presentaría como simplemente inferior. ${ }^{30}$ La pobreza es, de acuerdo con Heidegger, un modo de la carencia, un modo del no tener. Pero la pobreza es también un modo del encontrarse humano, de ánimo pobre, humilde o melancólico. Sin embargo, esta relación con el encontrarse humano no dirime la diferencia entre el hombre como configurador de mundo y el animal como carente de mundo. El mundo es, dice Heidegger «lo ente respectivamente accesible y lo ente tratable ${ }^{31}$ y en esa relación de acceso y trato el hombre lo configura. Es aquí donde encontramos la grieta que separa de un modo tajante la lectura heideggeriana de von Uexküll de la lectura deleuzeana. El mundo del animal no es, para el filósofo alemán, otro diferente al del hombre. Es el mismo mundo respecto del cual el hombre tiene mayor accesibilidad. El medio del animal no es un medio específico y cualificado, sino su mero entorno, que incluye otros animales, plantas, al propio hombre. Ese medio no es otra cosa que el lugar donde el animal habita, los peces en el agua, el escarabajo en el tallo y la tierra. Pero ¿por qué no es este el mundo circundante de von Uexküll? Uno podría decir que, efectivamente, el mundo animal tiene que ver también con lo que es accesible para él, con aquello frente a lo cual tiene la capacidad de ser afectado y de actuar. De hecho el análisis del mundo animal en Heidegger parece orientarse al desarrollo de la pregunta por el mundo en general con el objeto de mostrar justamente este diferencial respecto de la relación entre los entes y el mundo. ${ }^{32} \mathrm{El}$ mundo no pertenece a todos los entes por igual, o al menos no todos los entes son en el mundo por igual. Pero aquí está el nudo de la cuestión. Si el mundo no es accesible por igual, dicha accesibilidad debería evaluarse con algún concepto o medida que trascienda el propio mundo del ente en cuestión, y que permita, así, evaluar también el mundo del hombre, de otro animal o de la piedra.

Cuando Deleuze ubica a J. von Uexküll, implícitamente, como «un lejano sucesor de Spinoza ${ }^{33}$ realiza una lectura del biólogo que evita explícitamente la deriva hacia toda diferencia o superioridad del hombre respecto del animal.

29 J. von Uexküll, Mondes animaux et monde humain. Suivi de Théorie de la signification. tr. P. Muller. Paris: Denoël, 1965, p. 26. [cursiva mía].

30 Cfr. M. Heidegger, Los conceptos fundamentales de la metafísica. Mundo, finitud, soledad, tr. A. Ciria. Madrid: Alianza, 2007, pp. 244-245.

31 Ibid., p. 247.

32 Cfr. B. Buchanan, Onto-ethologies. The Animal Environments of Uexkull, Heidegger, Merleau-Ponty and Deleuze, Albany: State University of New York, 2008, p. 55.

33 G. Deleuze y C. Parnet, Dialogues. Paris: Flammarion, 1996, p. 74. [Hay traducción castellana: Diálogos, tr. J. Vázquez. Valencia: Pre-textos, 1980.] 
Tampoco se trata de recurrir a la figura del animal para hablar de la impotencia humana en el mundo actual, la impotencia que se vuelve temple anímico determinante y que suspende la relación técnica del mundo, su curvatura en torno al sujeto como punto desencadenante de las acciones posibles. De hecho, para J. von Uexküll la pobreza de afectos implica una riqueza de acción, y en ningún caso carencia respecto de un modo más rico de relación con el mundo. Al asociar la noción de pobreza con un cierto encontrarse del hombre e incluso llegar a valorizar la experiencia de la pobreza como un gesto deseable de ascetismo mundano que dejaría el mundo como posibilidad, Heidegger se acerca más al Benjamin de «Experiencia y pobreza»-aquella que describía la imposibilidad de relación con un mundo que luego de la guerra había perdido su posibilidad de ser narrado- que a la determinación del animal en von Uexküll. Para el biólogo «la pobreza del medio condiciona la certeza de la acción, y la certeza es más importante que la riqueza». ${ }^{34}$ La pobreza del mundo circundante del animal no puede ser leída de ningún modo bajo la lógica del aturdimiento, de una imposibilidad de disponer sino que en su mundo cada animal es el centro y el mundo se encuentra saturado por los afectos que lo componen. El célebre ejemplo de la garrapata tiene como objeto dar cuenta de la particularidad de un mundo saturado en su sobriedad. Esta sobriedad afectiva es en cierto modo una máxima del manifiesto que abre Mil mesetas, «Rizoma», y que augura un múltiple entendido como n-1. Los ejemplos son elocuentes: la pantera rosa, los personajes en fuga de Godard, Glenn Gould. En cada caso no se trata de un enriquecimiento de la relación con el mundo sino de una intensificación afectiva.

Es en Kafka. Por una literatura menor donde encontramos las primeras formulaciones de la relación que luego se soldará entre arte y animalidad a partir de Mil mesetas, y es en los textos que rodean el inicio de la década del 80 donde vemos la aparición frecuente de los mundos de von Uexküll. La breve mención implícita en Diálogos es acompañada de la filiación explícita en el texto sobre Spinoza del 81, para luego reforzarse en Mil mesetas e incluso reformularse a través de un vocabulario bergsoniano en los libros sobre cine. Es que en la noción de Umwelt encontramos el centro del vínculo entre arte y afectos. Y no sólo allí, sino más precisamente en la comprensión musical que von Uexküll tiene de la naturaleza, y por lo tanto de la relación entre mundos inconmensurables entre sí. La función territorio / desterritorialización es la que describirá el hacer propio del arte, a través del concepto de «ritornelo». Así, el vínculo que Deleuze establece con el problema del arte, se encuentra siempre íntimamente ligado a un modo de hacer propio del animal. La metáfora musical que recorre el texto de Uexküll encuentra de este modo, en la noción de «ritornelo», su expresión acabada.

34 J. von Uexküll, op. cit., p. 26.

Contrastes vol. XXI-Nº 1 (2016) 


\section{LA MODULACIÓN DELEUZEANA: DE LA UMWELT AL RITORNELO}

Como hemos indicado, la noción de Umwelt resulta central en la consideración heideggeriana de von Uexküll en tanto que permite, en el argumento de Los conceptos fundamentales de la metafísica, abrir cabalmente el problema del mundo en tanto tal. Sin embaergo, Brett Buchanan ha señalado que a diferencia de Heidegger o de Merleau-Ponty el uso deleuzeano y guattariano de von Uexküll se caracteriza por no tomar este concepto fundamental como punto de partida. ${ }^{35}$

Como sucede a menudo con el particular uso que hace Deleuze de sus fuentes, el concepto de Umwelt es tomado como eje de una transvaloración, aquella que cruza y superpone a von Uexküll con Spinoza. Se trata de pensar la noción de Umwelt bajo la lógica afectiva spinoziana, y al mismo tiempo, la ética como una etología. El cruce entre ética y etología tiene, a su vez, el objetivo de deslindar ambos términos del vínculo con el comportamiento, a favor de una lógica de la potencia. De lo que se trata es de qué es capaz cada cuerpo, cada animal, cada individuación. Potencia de afectar y de ser afectado. De ahí que aparezca, en Spinoza filosofía práctica pero luego nuevamente en Mil Mesetas, la afirmación de que hay más diferencias entre un caballo de carreras y un caballo de carga, que entre el caballo de carga y el buey. ${ }^{36} \mathrm{Se}$ modifica levemente el problema de los mundos circundantes respecto de cómo es expuesto en von Uexküll, desde la especie hacia la construcción afectiva, que en cierto modo corresponde al movimiento que lleva del organismo como fundamento desde el cual se piensa el horizonte de posibilidades de acción hacia los devenires concretos en los que un cuerpo entra. Es en la meseta dedicada a los devenires, donde la transvaloración del mundo circundante alcanza su función propiamente deleuzeana. Se trata de pensar cómo se articulan los devenires, y aquí, lo que interesa es menos la particularidad específica que la composición afectiva.

Pero von Uexküll es un bajo continuo aun en otro sentido. Los mundos animales que el biólogo describe son inconmensurables, es decir, no hay comunicación entre mundos, sino una gran composición de la naturaleza que permite que la araña teja su tela justo a la medida de la mosca sin tener un vínculo real con la mosca. Esa composición que la naturaleza supones es a menudo asimilada a la lógica musical. Son incontables las referencias en este sentido en los textos de von Uexküll. La idea de una conformidad a plan en la naturaleza articularía todos los mundos animales como si formaran parte de una gran partitura. Cada mundo es como una melodía que tiene en otro

35 Cfr. B. Buchanan, op. cit. p. 177.

36 Cfr. G. Deleuze, Spinoza, filosofía práctica, ed. cit., p. 151 ; G. Deleuze y F. Guattari, Mil mesetas. Capitalismo y esquizofrenia, tr. J. Vázquez. Valencia: Pre-textos, 2002, p. 261. 
mundo su contrapunto exacto que la completa y a su vez le brinda las notas y colores que le responden.

En el mundo biológico es todo armonía, todo melodía, ya que, aunque los momentos no estén allí para encadenar los movimientos unos a otros, subrayan las sensaciones de contenido de los colores y de los sonidos en una secuencia oscilante de silencios, breves y largas. ${ }^{37}$

La flor cuya corola responde exactamente al aguijón de un insecto no tiene con él un origen evolutivo común. Y sin embargo esas formas complementarias deben entenderse bajo la partitura común de la naturaleza. Esta inspiración musical está a la base del concepto de ritornelo y encuentra en el ejemplo de Messiaen quizás el caso más elocuente. El compositor intuyó tempranamente el valor musical del canto de los pájaros, y aunque evidentemente no es el primer músico que los utiliza como material compositivo, parece ser el primero en tomarlos realmente en serio. ${ }^{38}$

A pesar de que Messiaen habría notado cantos de pájaros desde los años '20, es recién en 1941 en el Quatour pour la fin du temps cuando un pájaro entra por primera vez en escena. A propósito de las novedades musicales introducidas por el Quatour pour la fin du temps, Roger Nichols señala dos direcciones. Por un lado, y siguiendo un poco literalmente el título de la obra y su escritura, la de cierta poética de la abolición del tiempo, cuyo fundamento sería el uso extendido de los ritmos no retrogradables. El palíndromo rítmico tendería hacia un distanciamiento del tiempo cronológico entendido en términos de intencionalidad o direccionalidad. Sin embargo, para Nichols no es ésta la innovación más revolucionaria, sino la segunda novedad que introduce la obra: la inclusión del canto de los pájaros. ${ }^{39}$ En esa misma época, en su Technique de mon langage musical, le dedica un breve capítulo, donde explica su utilidad compositiva: no se trata de imitar fielmente el sonido reconocible del canto, sino de reconstruir las relaciones rítmicas y melódicas, imposibles para un ejecutante humano. Este matiz, no imitar sino reconstruir las relaciones de la naturaleza, lejos de mostrar el resurgimiento de la vieja fórmula, cara a las artes visuales antes que a la música, del arte como imitación de la naturaleza, descubre un modo inédito de comprender la imitación. El hombre no copia algo del pájaro sino que adquiere posturas, comportamientos, modos de hacer mundo, propios del pájaro. Se deshumaniza en el pájaro. El uso de cantos de pájaros encuentra

37 J. von Uexküll, Cartas biológicas a una dama, tr. T. Bartoletti y C. Nicolás. Buenos Aires: Cactus, 2014, pp. 93-94.

38 Cfr. R. Sherlaw Johnson, "Birdsong" en Peter Hill [ed.] The Messiaen Companion, Amadeus Press, 1994, p. 249.

39 Cfr. R. Nichols, Messiaen, London: Oxford University Press, 1975, pp. 29-31. 
su expresión más acabada en el Catalogue d'oiseaux, ciclo de trece piezas para piano donde cada una lleva el nombre de un pájaro. El catálogo presenta cada vez un retrato del personaje musical que el pájaro parece interpretar. Pero el personaje es presentado con su pequeño fragmento de mundo, llevando la lógica territorial al extremo: no sólo el canto delimita el territorio, a la vez el paisaje se inmiscuye y queda retratado junto con el personaje, formando un bloque donde el territorio ve sus límites minados.

Es necesario llevar las relaciones entre-mundos, entre-medios, más allá de la estructura de la composibilidad. La intuición de la naturaleza como música requiere todavía de una operación sobre los medios que transforme el valor de las marcas y los signos, que deben pasar de un valor puramente activo y reactivo hacia un valor expresivo. ${ }^{40}$ Esta es la diferencia entre un medio y un territorio: el territorio permite comprender el origen del arte como composición expresiva, y solo así adquiere cabal sentido la intuición de la naturaleza como música. Cuando Deleuze y Guattari afirman que el territorio es un efecto del arte, están modificando la dimensión de las marcas. «Las marcas territoriales son readymades ${ }^{41} \mathrm{y}$ esta definición resulta por demás sugerente para comprender su dimensión expresiva. Un ready-made no es creación sino gesto puesto a irradiar sentido. Es menos un objeto descontextualizado que un escenario creado en torno a un objeto cualquiera que deviene centro de escena. De allí que advenga rápidamente el ejemplo del pájaro australiano, Scenopoïetes dentirostris, ${ }^{42}$ que es justamente el poeta de la escena, el que construye el escenario, y es esta construcción del medio como escenario lo que lo convierte en territorio. La diferencia entre un medio sin más y un territorio es la dimensión expresiva de la escena, donde cada objeto necesariamente se pone expresar. Es posible arribar así al vínculo entre música y naturaleza desde un lugar novedoso: el ritornelo es en cierto sentido la traducción deleuzeana y guattariana, del mundo circundante hibridado con el concepto de modulación. Lo que ha pasado entre uno y otro es que el valor musical de la naturaleza en von Uexküll y el de la individuación permanente simondoniana alcanzan aquí su dimensión estéticoexpresiva adecuada. Este andamiaje teórico permite a Deleuze enriquecer el concepto guattariano de ritornelo, que no sólo sirve para una conceptualización de la música, sino que se erige en ¿Qué es la filosofía? como concepto clave de bóveda de toda filosofía del arte. No es posible comprender el concepto de ritornelo si no es alineándolo con la reflexión sobre el animal, sin la cual quedaría relegado a una lógica de la morada que restaría romántica.

40 G. Deleuze y F. Guattari, Mil mesetas. Capitalismo y esquizofrenia, ed. cit., p. 323.

41 Ibíd.

42 No casualmente los autores modifican sutilmente la nominación científica (scenopoeetes dentirostris) para remarcar poietés. 
GuAPALUPE LuCERo es profesora de estética y filosofía del arte en la Universidad de Buenos Aires.

Línea de investigación:

Realizó su tesis doctoral sobre la filosofía de la música en Gilles Deleuze. Investiga en el área de filosofía contemporánea y estética.

\section{Publicaciones:}

«Musique-pratique: du formalisme au partage du temps» en Filigrane, vol. 13, n¹1, Premier semestre 2011, Paris, Delatour France, (ISSN 1773-9128) pp.115-126.

«Agotar la lengua . Beckett a través de Deleuze» en Daimon. Revista Internacional de Filosofía, Ediciones de la Universidad de Murcia N55, Año 2012 (ISSN 1989-4651).

Correo electrónico: guadalupe.lucero@gmail.com 